\title{
Homo capax
}

\author{
Patricio Mena Malet ${ }^{l}$ \\ UNIVERSIDAD ALBERTO HURTADO
}

1. La obra de Paul Ricoeur se resiste, según su propio testimonio, a ser pensada a partir de un gran hilo conductor, pues habitualmente se construye desde las interrogantes y aporías que han quedado como restos en los caminos previamente recorridos por el autor. Cada libro suyo es una verdadera apuesta por la navegación de ciertos senderos epistemológicos que lo han interpelado, a saber: la fenomenología, las filosofías de la religión, el psicoanálisis y la escuela de la sospecha (Marx, Nietzsche y Freud), la semiología, la lingüística, las teorías de la metáfora y las teorías narrativas, la historiografía, la sociología, la filosofía analítica, las neurociencias, la exégesis bíblica, etc. Como se puede apreciar, el espíritu filosófico de Ricoeur apuesta por lo que él mismo ha llamado la vía larga de la comprensión ${ }^{2}$ restándose de cualquier intento fundacional y fundamental. En este sentido, Ricoeur funda su reflexión en la creencia en la multiplicidad de sentido, en el conflicto interpretativo, pero que tiende a la unidad, y espera estar en la verdad ${ }^{3}$. Este impulso de su obra vuelve complejo el querer apostar por un gran hilo conductor, pues las hebras de su pensamiento están entrelazadas y a la vez cortadas.

1 Este artículo ha sido redactado en el marco del Proyecto Fondecyt $\mathrm{N}^{\circ} 11100061$. Debo agradecer a Olivier Abel y Catherine Goldenstein que me permitieron trabajar durante el mes de mayo de 2011 en la Biblioteca del Fonds Ricoeur, pudiendo consultar textos inéditos y artículos publicados del autor de difícil acceso. También debo expresar mi agradecimiento al IMEC de Caen, que me ha permitido consultar correspondencia privada de Ricoeur así como literatura secundaria también de difícil acceso. Esta estadía de investigación ha sido apoyada por el proyecto Fondecyt $\mathrm{N}^{\circ} 11100061$.

2 Cf. P. RICOEUR, «Existence et herméneutique», en Le conflit des interprétations (Paris 1969). La vía larga de la comprensión implica un rodeo por los símbolos y los textos, por el análisis y la reflexión, por la explicación y descripción.

3 Cf. P. Ricoeur, Histoire et Vérité (Paris 2001) 66. 
Sin embargo, es el propio Ricoeur quien propone como línea directriz de su obra la cuestión del obrar humano, del yo puedo o de las capacidades por las que se comprende el sujeto. «A primera vista, confiesa el filósofo francés, mi obra es muy dispersa; ella aparece así porque cada libro se organiza alrededor de una cuestión limitada: lo voluntario y lo involuntario, la finitud y el mal, las implicaciones filosóficas del psicoanálisis, la innovación semántica en obra en la metáfora viva, la estructura lenguajera del relato, la reflexividad y sus estadios. No es más que en los últimos años que he pensado poder situar la variedad de estas aproximaciones bajo el título de una problemática dominante; le he dado por título el hombre actuante o el hombre capaz» ${ }^{4}$. Y por su parte, Jervolino agrega: «Si este "hilo mantenido" que subtiende toda la investigación del autor está constituido por el "hombre capaz", es preciso entonces afirmar que se ha mantenido fiel toda su vida a la idea de una filosofía que se reafirma en sí misma, pero que deviene una actividad para pensar y promover en sus formas múltiples la humanidad del hombre. Como él mismo decía en un texto de juventud dirigido a jóvenes estudiantes cristianos: "el combate por la verdad es ahora un combate por un nuevo humanismo" ".

La temática del hombre capaz puede ser considerada entonces una de las grandes líneas directrices de la obra filosófica de Ricoeur que culmina en Parcours de la reconnaissance (2004), siendo parte de un largo itinerario que comenzó a ser recorrido a partir de los tomos 1 y 2 de Philosophie de la volonté (1950-1960) y que alcanza su desarrollo fundamental en Soi-même comme un autre (1990), obra en la que Ricoeur examina el yo puedo en sus diversos empleos: yo puedo decir, actuar, narrar y narrarme, como también imputarme las consecuencias de mis acciones. En obras posteriores, como en los dos tomos de Le juste (1995 y 2001), La mémoire, l'histoire, l'oubli (2000), Sur la traduction (2004) y finalmente en Parcours de la reconnaissance (2004), Ricoeur reflexionará sobre otras capacidades a partir de las cuales el sujeto se reconoce como un yo puedo, a saber: yo puedo juzgar, perdonar, reconocer, recordar y traducir. Y si se atiende a las obras anteriores que conforman su hermenéutica reflexiva y textual, por ej. Le conflit des interprétations (1969) y Du texte à l'action

4 Citado por Domenico Jervolino, P. RICOEUR. Une herméneutique de la condition humaine (Paris 2002) 44.

5 Idem., p. 45. 
(1986), podrían agregarse otras variantes del yo puedo tales como: yo puedo simbolizar, conflictuar, interpretar y comprender. Es, sin embargo, más o menos claro que cada una de estas capacidades se sostiene en la capacidad de actuar, de efectuar distintas acciones, de la que tal vez la más fundamental sea la de hablar que, por una parte, nos permite designarnos a nosotros mismos y, por otra, abrirnos y mantenernos en situación de interlocución.

2. ¿Cómo comprender la fenomenología del hombre capaz desplegada por Ricoeur a lo largo del itinerario de su reflexión? Ciertamente, cuando nuestro autor dice "hombre capaz» dice con ello «hombre actuante», sujeto que despliega su existencia a partir de sus poderes, de sus capacidades. En suma, el hombre capaz o actuante es aquel que puede retomarse reflexivamente a sí y atestiguarse en su humanidad a partir del modo como toma la iniciativa en el mundo, de la manera como se vuelve hacia este, hacia las cosas y los otros, pudiendo reconocerse a sí mismo tanto en sus obras como en el movimiento de su existencia hacia estas. "Es la humanidad, afirma Ricoeur, lo que llamo "Sí-mismo" en definitiva, la cualidad humana, el hecho de poder considerarse como el autor de sus propios actos, como siendo capaz de acciones intencionales, de iniciativas que cambian realmente el curso de las cosas, como pudiendo situarse en un relato de vida, como siendo a la vez el narrador y el personaje de su propia historia. Es esa humanidad, no en el sentido extensivo del conjunto de hombres, sino que intensivo de la cualidad humana: lo que hace que un hombre sea un hombre. He ligado por consiguiente esta noción de humanidad, continúa Ricoeur, con la capacidad reflexiva fundamental de designarse a sí mismo como aquel que habla, como aquel que actúa, como aquel que narra, "se narra" y como aquel que se siente responsable y a quien las consecuencias de sus actos pueden serle imputadas» ${ }^{6}$. De este modo, las capacidades o poderes del hombre son el lugar de desciframiento de la humanidad del hombre. Es también la instancia a partir de la cual este se atestigua como un sí-mismo, vale decir como sujeto que se comprende en la pluralidad del despliegue de

6 P. Ricoeur, «Une entretien avec Paul Ricoeur. Soi-même comme un autre», (propos recueillis par G. Jarczyk), Rue Descartes. Revue du Collège International de Philosophie, 1-2. 
su existencia: no se afirma ni un yo puro ni tampoco el yo (ego ille $)^{7}$ pascaliano, sino que se atestigua un sí-mismo como «subjetividad plural y declinable que no es la propiedad exclusiva del "yo" y que «encuentra su lenguaje adecuado, coextensivo en el conjunto del campo de la actividad humana» ${ }^{8}$. De este modo, si la cuestión del «hombre capaz» remite a la reflexividad, por tanto a la posibilidad que tiene el sujeto de retomarse y recobrarse a sí a partir del despliegue de su existencia en sus capacidades, entonces esta nos abre también a la relación que mantiene el sujeto con la alteridad en sus múltiples formas, por ejemplo, la del cuerpo propio, de la conciencia y del otro, que en el estudio décimo de Soi-même comme un autre Ricoeur llama el "trípode de la pasividad» y que viene a completar la reflexión sobre la pasividad que elaborara treinta años antes en la primera parte del tomo dos de Philosophie de la volonté, a saber L'homme faillible. . Que el hombre se atestigüe en sus capacidades, que confíe en sus poderes -de decir, actuar, narrar y narrarse, de asumirse responsable de sus acciones- para «asegurarse a sí mismo como actuante y sufriente» ${ }^{10}$, significa que entre sí y sí mismo media una distancia que es infranqueable.

La atestación como confianza en los poderes del hombre, en su humanidad en definitiva, da cuenta de un cambio de registro epistémico importante: lo atestiguado no es el yo propio de la filosofía reflexiva de Descartes o Husserl, cuyas pretensiones de autofundación y autotransparencias son absolutas. Lo atestiguado no es un sujeto trascendental, un ego puro, sino un cogito -herido y quebrado- implicado con la alteridad, que está llamado a ser en relación con lo otro. En este sentido, el sí-mismo como sujeto capaz destituye la cuestión del sujeto por el sujeto en cuestión, puesto en cuestión. Antes de pensarlo como origen y comienzo del sentido, Ricoeur se aboca a la tarea de responder a la pregunta ¿quién soy?, ¿quiénes somos?, haciendo de esta pregunta el verdadero núcleo de su interrogación. Así, el sujeto se dona como una tarea por

7 Cf. V. CARRAUD, Linvention du moi (Paris 2010).

8 D. JerVOLINO, Ricoeur. Herméneutique et traduction (Paris 2007) 12.

$9 \quad \mathrm{Al}$ respecto, Ricoeur afirma en Réflexion faite (Paris 1995, p. 29) lo siguiente: «La verdadera reconsideración del hombre falible habría que buscarla más bien en el último capítulo de Soi-même comme un autre donde las tres modalidades de alteridad -la del cuerpo, la del otro, la de la conciencia moral-ocupan un lugar comparable al asignado entonces a las figuras de la falibilidad».

10 P. Ricoeur, Soi-même comme un autre (Paris 1990) 35. 
realizar y comprender, como una conquista que exige múltiples desvíos y conflictos interpretativos. Se entiende entonces por qué nuestro autor vuelve productivos los diálogos con otras disciplinas, por ejemplo en Soi-même...: la filosofía del lenguaje (estudios I y II), la filosofía de la acción (estudios III y IV), la teoría narrativa (estudios V y VI) y la filosofía moral (estudios VII-IX), reservando para el estudio décimo y final la cuestión ontológica, «¿Hacia qué ontología?», donde volverá sobre la atestación y el trípode de la pasividad a partir del cual se recobra y comprende el sí-mismo.

3. Por otro lado, la distancia de la que hablábamos remite a la opacidad que experiencia el sí-mismo a raíz de su relación implicada con la alteridad. No es posible una comprensión inmediata y transparente de sí porque el quién que soy, y no tan solo eso que soy, se constituye de manera totalmente imbricada con lo otro: de una parte, el sí-mismo es como otro para sí en el modo como hace la experiencia de su corporeidad, por ejemplo, en tanto órgano del querer y fuente de motivaciones y, al mismo tiempo, como resistencia de ese mismo querer y esfuerzo por vencer. El sí-mismo al hacer la experiencia de sí no se halla prístinamente a sí, sino que se encuentra complicado por un involuntario que le aporta motivos para decidir, para proyectar y actuar, pero que también le ofrece resistencias al propio despliegue del querer y obrar humanos. Por otra parte, esta alteridad de sí despierta al sujeto a la tarea de tener que ser en relación con lo otro de sí. Los ejemplos al respecto se pueden multiplicar: así, manteniéndonos en los análisis de Le volontaire et l'involontaire, el involuntario absoluto -el carácter, el inconsciente y la vida-, es vivido como una necesidad a la que hay que consentir y que nos confronta a una libertad humana, finita y frágil. O si volvemos a Soi-même comme un autre, la mismidad, como identidad sustancial ${ }^{11}$, como un modo de ser lo mismo a pesar del paso del tiempo, está todavía implicada en la alteri-

$11 \mathrm{Al}$ respecto, Françoise Dastur afirma lo siguiente en su artículo «L'ipséité: son importance en psychopathologie» (en PSN, volume III, numéro 12, mars-avril 2005, p. 92): «Se trata luego de distinguir los dos sentidos principales de la identidad que reenvías a la oposición de los términos latinos ipse e idem. Estamos frente a la problemática propiamente ricoeuriana de la ipseidad. Ricoeur explica, en efecto, que la ipseidad, contrariamente a la mismidad, que connota el término latino idem, del que sale la palabra castellana "identidad", no se caracteriza por la presencia de un nudo invariante de la personalidad, tal como el carácter, sino por el mantenimiento 
dad. Así, cuando Ricoeur toma el carácter como modelo de la mismidad no lo define en cuanto invariable, sino que abierto a modificaciones. Al respecto, permítaseme una larga cita de Bernard Ilunga Kayombo por la fuerza de su claridad: «El problema de la identidad-mismidad del sí-mismo se vincula finalmente al de la búsqueda de lo que, en la constitución de sí-mismo, sigue siendo el mismo o invariante a través del tiempo. Precisamente, lo que sigue siendo el mismo, y que el tiempo no tiene éxito en suprimir, es decir de volver enteramente distinto, es el carácter [...]. El carácter es aquí definido como "el conjunto de las marcas distintivas que permiten reidentificar un individuo humano como siendo el mismo". Bajo el concepto de carácter están contenidas la identidad numérica, la identidad cualitativa y la permanencia en el tiempo. Pero contrariamente al modo como ha sido definido en los trabajos anteriores de Ricoeur, el carácter no tiene aquí carácter rígido de inmutabilidad. La inmutabilidad del carácter es bastante particular, dice el Ricoeur de madurez, pues el carácter es ciertamente dado, pero también está abierto a modificaciones a favor, por ejemplo, de las identificaciones con valores, con personajes, etc. Estas identificaciones, al final, terminan por sedimentarse en el polo mismo de sí-mismo. De donde la definición siguiente y actual del carácter: 'el conjunto de disposiciones durables en las que se reconoce una persona» ${ }^{12}$.

El hombre capaz de decir, de narrar y narrarse cuando se designa a sí mismo no designa un sujeto transparente para sí mismo, sino que acepta

de la cohesión de sí a través del tiempo cuyo paradigma es la promesa, de la que se podría decir que juega en Ricoeur el rol atribuido a la resolución por Heidegger».

12 La cita continúa del siguiente modo: «Por tanto, en el carácter, se cristaliza "el conjunto de las identificaciones adquiridas por las que el otro entra en la composición de lo mismo" (SA 146). El sí-mismo se reconoce también por su identificación, por ejemplo, con valores, con normas, ideales, modelos, héroes, etc. Esta identificación es una manera de ser permanente que permite al sí-mismo reconocerse y, más aún, al otro reconocernos. Cuando alguien dice de sí que no se reconoce en tal o cual acto cometido, recurre implícitamente a esas disposiciones sedimentadas que son como carnet privado, incluso público, de identidad. Aquí hay intrusión de lo otro en lo mismo [...] Esto quiere decir que incluso lo mismo de sí-mismo no puede pensarse de punta a cabo sin la intervención de lo otro. El carácter no tiene por consiguiente ese carácter absoluto de inmutabilidad. Porque estas identificaciones se instalan y cristalizan en el carácter a favor del tiempo y pueden, siempre a favor del tiempo, deshacerse y hacer lugar a otras identificaciones [P. RICOEUR, De l'attestation de soi (Paris 2004) 144-146]. 
la tarea de ejercitarse en la comprensión de sí. Este sería tal vez un lugar de aproximación entre la hermenéutica del sí-mismo ricoeuriana y la hermenéutica del sujeto de Foucault, quien a partir del tomo tercero de su Historia de la sexualidad y en sus últimos cursos dictados en el Collège de France, se dedica a interrogar las técnicas del cuidado y conocimiento de sí. Un sujeto que se ejercita en la comprensión de sí -esta nos parece una tesis común entre ambos autores- no sale invicto tras su realización. Así refiriéndose Foucault a la espiritualidad cristiana afirma lo siguiente: «La espiritualidad postula que la verdad nunca es dada al sujeto con pleno derecho. [...] Postula que es preciso que el sujeto se modifique, se transforme, se desplace, devenga, en una cierta medida y hasta un cierto punto, otro para que él mismo tenga derecho al acceso a la verdad. La verdad no le es dada al sujeto sino al precio de poner en juego el ser mismo del sujeto» ${ }^{13}$. Porque ser sí-mismo es estar complicado por la presencia del mundo y del otro, porque este no es ni el origen ni el dueño de sí, es que la comprensión de sí requiere de mediación e interpretación, lo que conlleva sus riesgos, tal como lo muestra el texto de Foucault recién citado. Ser capaz de volver sobre sí no implica ningún éxito al respecto, si se espera dar con el sí que comenzó la indagación: el sí-mismo está en juego en el acto mismo de la comprensión y de alguna manera es inimaginable para sí, por lo que la reflexión es verdaderamente una aventura comprensiva, una experiencia; es decir una travesía que conlleva peligro y riesgo, esto si atendemos a la raíz indogermánica PER presente en empeiría, experiri, expérience y experiencia. Al respecto, Jean Greisch afirma lo siguiente: «Háblese de empeiría en griego, de expiriri en latín, de Erfahrung en alemán, de expérience en francés, de experience en inglés, etc., tenemos siempre que ver con la plurivocidad desconcertante de la raíz indogermánica per-. Ella connota también al enemigo y al peligro (periculum) como la travesía o el pasaje, asimilado a un auténtico traspasamiento (término que jugará un rol crucial en la descripción eckhartiana de la experiencia mística). Cualquiera que sean las experiencias concretas a las que se relacionan todos estos vocablos, ellas gravitan alrededor de un mismo centro de sentido: la idea de una travesía peligrosa, es decir de una "experiencia" de alto riesgo, peligrosa por definición. En alemán, la misma raíz vincula el término Erfahrung, que connota el itinerario y la travesía, y el término Gefahr: el peligro y

13 M. Foucault, L’herméneutique du sujet (Paris 2001) 17. 
el riesgo» ${ }^{14}$. Y en un sentido semejante Claude Romano dice lo siguiente: «Experienciar es dejarse alcanzar por lo que viene a nosotros [...] La experiencia es una travesía, lo que supone una distancia e intervalo y un franqueamiento, de sí a sí, por la cual solo podemos acoger lo que nos adviene, adviniendo a nosotros mismos como otro» ${ }^{15}$.

Ricoeur no ha puesto demasiada atención al carácter trastocante del encuentro con lo otro por lo que no hay en su filosofía una reflexión sobre la experiencia en el sentido de aventuramiento y de riesgo, al contrario de Levinas, Maldiney o Claude Romano. Sin embargo, no cabe duda que el hombre capaz no es un ego transparente para sí, precisamente porque es un ser contingente, es decir que entra en contacto con el mundo y los otros, y hace, por tanto, la experiencia de sí vuelto hacia las cosas, enredado en ellas, opacado por la presencia del mundo. Si nuestro autor no pone suficiente énfasis en el riesgo y la aventura de la experiencia, no deja de resaltar sin embargo el itinerario que debe recorrer el sí-mismo para recobrarse comprensivamente a sí. El détour ricoeuriano, que realiza cada vez en sus obras, es por tanto un modo de asumir el sentido que aporta la raíz indogermánica PER de experiencia: pues el rodeo por los signos, las obras y los textos, son ya, primeramente, un modo de atestiguar el carácter existencial del sujeto, en el sentido fuerte, es decir en cuanto sujeto fuera de sí volcado al mundo. Con ello Ricoeur reconoce al menos las siguientes tesis: a) el sí-mismo lo es siempre en relación con lo otro, es su apertura lo que hace del sujeto un sí-mismo y no meramente un yo; b) dicha relación supone la posibilidad de la pasibilidad, es decir de la afectación, de la hetero y autoafección, por lo que una de las notas distintivas del sí-mismo, en contraposición a la de un ego con pretensiones de autofundación y de transparencia, es su capacidad de entrar en contacto consigo mismo y con lo otro sin quedar inmune tras el encuentro; c) si el sí-mismo es tal a raíz del encuentro con el mundo y los otros, entonces no es él quien es su propio fundamento, siendo de alguna manera por sí y por otro a la vez; d) la autonomía y heteronomía propia del sí implica también una distancia vivida como extrañeza, como diferencia, y en este sentido el sí-mismo es primeramente opaco antes que transparente; e) pero la opacidad implica la posibilidad de

14 J. GREISCH, «Les multiples sens de l'expérience et l'idée de vérité, en Recherches de science religieuse, 2003/4, tome 91, 598.

15 C. Romano, L'événement et le monde (Paris 1998) 195. 
transparentar lo que se mantiene difuso, por lo que es necesario aplicarse metódicamente a la inspección de ese sujeto complicado por la alteridad, abierto y en relación con ella, para develarlo o explicitarlo. Una fenomenología del hombre capaz supone por tanto una hermenéutica del sí-mismo cuya finalidad es su explicitación a partir del rodeo de los símbolos, las obras, los textos, y el análisis. La condición para hablar de sí-mismo y no de ego, es que el primero es siempre a partir de la experiencia del encuentro con la alteridad y de la mantención de ese encuentro: solo sosteniéndolo se atestigua al sí-mismo como otro, pues este es fundamentalmente en el encuentro y no de otra manera.

De esta forma, el tema del hombre capaz no remite a un sujeto transparente para sí, sino a un sujeto abierto al mundo; un sujeto intencional que introduciendo su acción en el mundo, lo modifica. Ser un sujeto actuante es aventurarse a operar transformaciones a partir del obrar. Lo que implica a su vez el desvío para la comprensión de sí que ya señalábamos, pues las capacidades desde las que se retoma el hombre en su humanidad conllevan la posibilidad de la inscripción y objetivación de la existencia en el mundo a través de los objetos culturales y obras que producimos. No hay comprensión directa de sí, pues esta debe hacer el desvío por las objetivaciones que realizamos. «La primera verdad -yo soy, yo pienso- sigue siendo abstracta y vacía como invencible; le es preciso ser "mediatizada" por las representaciones, las acciones, las obras, las instituciones, los monumentos que la objetivan; es en esos objetos, en el sentido más amplio de la palabra, que el Ego debe perderse y reencontrarse» ${ }^{16}$.

Cada uno de estos argumentos nos permite concluir que el «hombre capaz» remite a un sí-mismo que no es dueño de sí, ni del sentido, que es por sí mismo pero también "por otro», que es autónomo pero también heterónomo. Esta relación implicada con la alteridad es también el fundamento de la opacidad constituyente del sujeto en el ámbito de la comprensión. Pues, "la atestación de sí, en una palabra, es fiarse de sus poderes para el conocimiento de sí-mismo, es reapropiarse el sentido de sí que los poderes depositan fuera de sí, es dejarse reinstruir sobre sí-mismo por sus propios poderes» ${ }^{17}$. El hombre capaz es un sujeto descentrado, fuera de sí, un existente en el sentido fuerte de la palabra. Y he aquí

16 P. Ricoeur, De l'interprétation. Essai sur Freud (Paris 1965) 53-54.

17 B. Kayombo, Paul Ricoeur. De l'attestation de soi (Paris 2004). 
una consecuencia tal vez poco explorada: el descentramiento de sí solo puede conducir al sí mismo hacia lo inesperado de sí, vale decir hacia su carácter inimaginable. Si este puede cava vez perderse en las obras, en los signos, en el mundo y en el otro, es porque es demandado, llamado o convocado por su presencia, exigido de responder de sí y de lo otro. El movimiento hacia las cosas por las que se comprende el sí-mismo no es solamente un modo de perderse en ellas, sino que primeramente una manera de perderse a sí. Pero, por otro lado, es necesario resaltar, antes que la negatividad de tal experiencia, su positividad, a saber: perderme a mí mismo implica, de alguna manera, esperarme a mí mismo, si así no fuera no se entendería que este persistiese en la búsqueda de sí, en la explicitación de sí por medio de la exégesis de los signos y los textos. No renunciar a la comprensión de sí implica confiar aún que sigue habiendo un sí-mismo y esperar hallarlo en el «aprendizaje de los signos»: pero, ¿qué es lo que se espera? Un sí-mismo, ciertamente, pero ¿cuál? La aventura propia de la hermenéutica reflexiva, aquella que confía en la posibilidad de un retorno a sí tras el rodeo de las mediaciones, está asentada en la espera de lo inimaginable de sí: si lo esperado es un sí-mismo y no meramente un ego, y si un sí-mismo es tal porque hace la experiencia del encuentro con la alteridad y de las transformaciones a las que se ve expuesto por la contingencia de tales encuentros, entonces no es posible esperar sino lo que es inimaginable de sí. Tal vez, el hombre capaz de metáforas puede aportar algunas luces al respecto. Sin embargo, por el momento bástenos con esta sugerencia.

4. ¿Qué quiere decir Ricoeur cuando plantea que la humanidad del hombre se deja comprender en las capacidades a partir de las que el sí mismo se retoma? ¿Se trata de una concepción esencialista: las capacidades -decir, actuar, narrar, comprenderse responsable de sus acciones- son aquellas por las cuales «el hombre es un hombre». Leyendo el texto antes citado al parecer la respuesta debiera ser sí. Bernard Ilunga Kayombo lo interpreta de este modo también. Sin embargo, Gaëlle Fiasse rechaza de plano esta tesis: «La capacidad, afirma la autora, no hay que comprenderla como al esencia del hombre, puesto que si Ricoeur reivindica una ontología del ser como potencia y acto, es en vista de oponerse a una filosofía esencialista, sustancialista. El movimiento está inscrito en el corazón del ser. La capacidad no es ni estática ni atemporal. No hay que 
pensar la dunamis del lado de la facultad o del de una forma que tendría que ser actualizada. La dunamis en el sentido ricoeuriano se inclina hacia el obrar, hacia la productividad de la que el hombre se reconoce capaz» ${ }^{18}$.

Ciertamente parece un error, tal vez provocado por el propio Ricoeur, pensar que las capacidades puedan ser pensadas como la esencia de la humanidad del hombre. Sin embargo, tampoco es fácil de decir por completo que no. El hombre verdaderamente se comprende y atestigua en sus capacidades y de las múltiples capacidades que posee y por las que se despliega como existente en el mundo, hay cuatro que parecen ser soporte del resto: el poder actuar, decir, narrar y narrarse e imputarse a sí mismo la responsabilidad de las acciones. Y de estas, el actuar pareciera ser aún su soporte: pues decir y narrar, son todavía un modo de actuar, y el considerarse a sí responsable responde todavía a un obrar; la capacidad de designarme a mí mismo. Sin estas capacidades no parece posible comprender al hombre en tanto hombre; y sin embargo es por ellas mismas que no se puede sostener un sujeto sustancial, por algunas de las razones que ya hemos examinado: ser un hombre capaz es estar en relación con la alteridad y estar fuera de su propio centro, lanzado hacia el mundo para obrar en él y modificarlo; es por tanto tener una comprensión opaca de sí que a su vez remite al quién que soy y no al que que soy. En este sentido, ¿habría que decir más bien que las capacidades son un a priori ${ }^{19}$ ? Bajo algún respecto sí, pues lo que soy es ciertamente lo que puedo, pero no me doy ni me arrostro quien soy en lo que puedo sin que este último sea respuesta al encuentro con las exigencias del mundo y del otro, es decir, sin que el ser capaz entre en relación con lo otro de tal modo que solo por esta es verdaderamente posible el despliegue de las capacidades por las que se atestigua a sí mismo: ser capaz implica una apertura y relación con lo otro de tal manera que el sí-mismo es a la vez

18 G. FIASSE, L'autre et l'amitié chez Aristote et Paul Ricoeur. Analyses éthiques et ontologiques, (Louvain-Paris 2006) 110.

19 «Si lo que me define, eso en lo que me reconozco, o eso en lo que se me reconoce, afirma Housset, es eso de lo que soy capaz, mi capacidad para decir o hacer no es a priori, pues es recibida en la gracia del encuentro. Es el llamado de las cosas que me vuelve capaz de compadecerme de ellas, es el llamado de mi amigo que me vuelve capaz de comprenderlo, es la manifestación del otro en su ser que me vuelve capaz de amarlo. En el amor precisamente, yo no determino a priori lo que puedo asumir, pues asumo lo que no sé poder asumir recibiendo al otro como puro don» [E. HoussET, La vocation de la personne (Paris 2007) 501]. 
por sí y por otro. El despliegue de las capacidades por las que entramos al mundo con nuestra iniciativa solo tiene sentido si entran y mantienen relación con la alteridad: en suma, las capacidades en las que nos atestiguamos son respuesta a los requerimientos del encuentro que hacemos del mundo y de los otros.

Así, no basta afirmar que somos capaces de decir o de actuar, sino que es necesario precisar las modalidades del decir y del actuar, y aquellas son bosquejadas en relación con el mundo, las cosas y los otros a los que respondemos. Yo no soy un sí-mismo capaz solo en cuanto dispongo de una capacidad, sino en la medida que modelo mi existencia a partir de ella de una manera singular. No solo soy capaz de actuar, sino que soy también y fundamentalmente capaz de reivindicar una acción ${ }^{20}$, un curso y un estilo de acción. Soy capaz por tanto de asumir y responder a las exigencias a las que me confronto cada vez que actúo, y eso implica comprender que somos por nosotros mismos - no dejamos de ser autónomos-, pero también por otro o por lo otro. Las capacidades son un modo de ser relacional, lo que significa que no me comprendo en ellas como un sí-mismo y un hombre capaz si no puedo asumirme y asumirlas, por tanto, si no son una respuesta a las exigencias del mundo y de los otros: son el modo de ser respondiente propio del hombre capaz.

No pudiendo sustraerme del hecho de "tener que responder», puedo siempre elegir «lo que responder»" ${ }^{21}$. Ser capaz es ser respondiente por un lado de las demandas que vienen del otro y del mundo, y por otro es responder de sí-mismo: responder a las exigencias y expectativas de las otras personas implica obrar como por ejemplo «pronunciar una ponencia ante un grupo de colegas», pero tal situación que demanda una respuesta de la que es imposible sustraerse -o doy en efecto esta ponencia o no la doy y me excuso, pero eso aún es responder defraudando por ejemplo las expectativas de los potenciales auditores-, exige una respuesta que implica el despliegue de las capacidades del conferencista, tales como poder articular un discurso, poder leer en el idioma exigido, etc., lo que en última instancia significa que aquel es capaz de reivindicar su acción, es decir asumirla como propia al tiempo de reivindicar el estilo de su respuesta. En el despliegue de mis capacidades me arrostro mi ser,

20 Cf. P. RicoeUR, «Note sur la personne», Le Semeur, N 7, mai 1936.

21 Cf. B. WALDENFELS, «L'autre et l'étranger», en L'herméneutique à l'école de la phénoménologie (Jean Greisch, dir.), (Paris 1995) 342. 
vale decir respondo de mí en mis acciones y respondo al otro al cual va dirigida mi acción, pero también respondo de él.

No basta decir que el sí-mismo es capaz puesto que el estilo de mis capacidades es primeramente una respuesta a las exigencias del mundo y del otro; y solo me arrostro mi ser por el despliegue de mis capacidades en tanto respuestas y no en tanto esencia de la humanidad del hombre, incluso si reconocemos a la humanidad ese "sentido intensivo" que subrayaba Ricoeur. Las capacidades son la mediación y el estilo a partir del cual asumimos la tarea de tener que ser y de tener que responder en última instancia: son el modo a partir del cual el hombre se arrostra su ser como tarea por realizar y no como naturaleza dada, como vocación por la libertad y no como destino irremediable.

Por otra parte, insistiendo en la tesis antes propuesta, si yo lo que puedo, no podría tampoco saber qué puedo sino tras o en el encuentro con lo otro. Así, amar a alguien es asumir lo que no sé, lo que de algún modo me encuentro solo al hallarme en relación con la persona amada. La capacidad de amar en tanto tal es una posibilidad, pero cuya posibilitación es dada por el encuentro singular con la otra persona; es este quien estiliza el poder de amar, quien le arrostra al sujeto amante la exigencia de delinear este poder de tal modo de singularizarse en él y singularizar también a la persona amada, en cuanto ella se halla a sí conforme al modo como se le da el amante, es decir como se le ama. No basta con decir «soy capaz de amar», pues es el despliegue singular de esta capacidad la que en última instancia le arrostrará al sujeto la tarea de tener que ser o de tener que asumirse en las acciones que reivindica.

5. Mas, ¿̇en qué sentido las capacidades son un modo de recobrarse a sí mismo? Para responder esta pregunta es preciso considerar que la " pacidad", tal como lo afirma Foessël, no se comprende sino sobre un fondo de negatividad e irracional $\aleph^{22}$, siendo este último el mal en su contingencia. Esta tesis también sostenida por Guillaume Le Blanc ${ }^{23}$ es a nuestro juicio crucial. Pues, por un lado sitúa a las capacidades

22 M. FOESSEL, «Les reconquêtes de soi», Esprit, «La pensée Ricoeur ", numéro 3-4, Mars-avril 2006, p. 291.

23 G. LE BLANC, «Penser la fragilité», Esprit, "La pensée Ricoeur ", numéro 3-4, Mars-avril 2006, pp. 249-263. 
ante la fragilidad y la vulnerabilidad: así por ejemplo frente al mal, «la capacidad no es otra que la inocencia, a saber la suspensión efectiva de la culpabilidad, aquella que condena, claro, pero que también impide actuar ${ }^{24}$. Se puede afirmar, entonces, que la capacidad es por una parte una reconquista de sí y, por otra que está confrontada siempre a su fragilidad o vulnerabilidad. Plantear las cosas en estos términos implica no solo apostar por la continuidad de la obra de Ricoeur -que iría del hombre culpable al hombre capaz ${ }^{25}$, sino también reconocer que no es posible oponer ambas temáticas, inclusive si Ricoeur le ha dado prioridad en sus últimas obras a la cuestión de las capacidades. Por otra parte, si estas últimas son una reconquista de sí, ciertamente pueden ser pensadas como expresión misma de lo que Ricoeur llama, siguiendo a Spinoza, el conatus en tanto deseo y esfuerzo por perseverar en la existencia. Si no hay capacidad sin experiencia de negatividad, sin que implique un "padecer para aprender", tampoco hay capacidad sin que esta sea un tipo de afirmación de sí ante la fragilidad y vulnerabilidad. Ser capaz implica pacientar la experiencia de lo negativo, pero también consentir la necesidad, afirmar el movimiento de trascendencia de la finitud y con ello la mixtura del ser humano, y atestiguarse a sí en los poderes por los que nos desplegamos en la existencia. Estos tres modos de decir sí el consentimiento, la afirmación originaria y la atestación, son tres maneras de perseverar en la existencia y tres formas de anhelo y deseo de ser que están a la base del hombre capaz. Ser capaz es consentir, afirmar y atestiguar. Pero ninguna de estas afirmaciones es absoluta y definitiva, pues se trata de tres afirmaciones que surgen tras la experiencia de la nada, de la negatividad para superarla y no para suprimirla. No sería justo afirmar entonces que la filosofía de Ricoeur lo es de la finitud; más bien se concentra en la mixtura de ser, en la mediación y el conflicto que es el ser humano.

24 M. FOESSEL, art. cit., 291-291.

25 Para el examen de esta tesis se pueden consultar las siguientes obras: de D. JERVOLINO, Paul Ricoeur. Herménéutique de la condition humaine (Paris 2005) y Ricoeur. Herméneutique et traduction (Paris 2007). O. MONGIN - M. FOessëL, Paul Ricoeur. De l'homme coupable à l'homme capable [Adpf, www.adpf.asso.fr, 2005]. G. FIASSE (dir.), Paul Ricoeur. De l'homme faillible à l'homme capable (Paris 2008). J. GreIsCH, Paul Ricoeur. Litinérance du sens (Grenoble 2002) y Qui sommes-nous? Chemins phénoménologiques vers l'Homme (novembre 2006), (Louvain-Paris 2009). 
«La autonomía, afirma Le Blanc, es ciertamente fragilizada por la vulnerabilidad, pero la vulnerabilidad es lo que constituye a la autonomía en autonomía humana. Así no es preciso comprender la autonomía como una alternativa a la vulnerabilidad, sino como profundización crítica ${ }^{26}$. El sujeto capaz se reconquista a sí afirmando su autonomía, pero esto lo hace asumiendo su vulnerabilidad; dice "sí», se dice sí a sí mismo, diciendo "no" a la impotencia en el obrar, inscribiendo su acción como una acción encarnada, esto es como una acción que requiere siempre de un esfuerzo y persistencia, pero también de una fatiga en última instancia insoslayable. Decir sí y decir no al mismo tiempo es lo propio del consentimiento a lo involuntario absoluto -la vida, el carácter y el inconsciente-, por ejemplo, que asumiendo la pasividad del encuentro con este no resigna la libertad sino que por ello mismo la afirma como una libertad humana. Consentir es decir sí a sí mismo y la necesidad vivida, pero también es decir no a esta necesidad que quisiera transformarse en destino.

6. Si hay cierta justeza en estos análisis, entonces habría que concluir que no hay tampoco consentimiento sin paciencia. La paciencia es primero paciencia de duración; por ella el sujeto de experiencia se descubre por un lado inquieto por la alteridad y se reconoce en su implicación, pero por otro hace la experiencia de la demora, de la prórroga constante de sí como existente. Y en este sentido, la paciencia es la experiencia del encuentro con la alteridad y de la imposibilidad de una comprensión acabada y transparente de sí. El hombre capaz en cuanto obrante pacienta la alteridad que lo demanda, que estiliza su acción y que le arrostra su ser; pero pacientar no es suprimir esta relación sino mantenerla y por tanto mantener el suspenso de sí; dejarse enviar hacia donde nuestros encuentros nos lanzan ${ }^{27}$. La paciencia es un sí a la persistencia de la relación con la alteridad y un sí al inacabamiento en términos comprensivos de sí. Tal como lo indica Emmanuel Housset: «la paciencia no es ni un apura pasividad dócil, ni la constancia de una voluntad, es un

26 G. LE BLANC, art. cit., 253.

27 Parafraseamos una frase de Emmanuel Housset. He aquí el texto: «Cada persona camina donde sus encuentros la envían, y es porque no tiene un rostro sino por la gracia de otro rostro que es en su venida su porvenir» [L'identité d'exil (Paris 2008) 350]. 
cierto modo de permanecer frente a lo que se da, que no es una simple permanencia en el tiempo de la sustancia, sino de durar manteniendo la relación ${ }^{28}$. Pero, también, al igual que el consentimiento, es un no: pues quien pacienta persiste en ser un sí aunque acepte ser vuelto hacia lo inimaginable de sí; afirma aún su autonomía aunque esta no tenga sentido sin la vulnerabilidad que la hiere.

Si las capacidades realmente se sostienen en esta dialéctica entre el sí y el no, entonces se podría afirmar que ellas no son expresión primera del proyecto por el que somos lanzados hacia nuestras posibilidades más propias, sino que son realmente respuesta al encuentro con la alteridad. La iniciativa del homo capax tiene su fundamento en la pasividad y en la pasibilidad como capacidad de afectación. Pues, antes que ser puramente iniciativa, el hombre capaz es también espacio de acogida. Pero entonces ¿¿cuál es el sí-mismo que es en el despliegue de sus capacidades? Es aquel capaz de arrostrarse su ser y de pacientarse a sí en tal arrostramiento: pues quien responde a las exigencias de la alteridad, está implicado por esta a tal punto que no puede ser un sí-mismo si no es porque su ser consiste en esta capacidad de hacer el encuentro con lo otro. No se podría decir sin embargo que el sí-mismo es el otro. Lo que me toca e irrumpe no soy yo, pero yo no podría ser este yo que soy sin haber hecho la experiencia de lo otro.

La paciencia no solo refiere a la pasividad, sino que connota la relación que el sujeto mantiene consigo mismo, con lo otro, con el presente y con el futuro; es constancia -la que no debe ser confundida con obstinación- disponibilidad y resolución, consentimiento y hospitalidad. Es así que la paciencia está llena de inquietud y de movimiento, de actividad e iniciativa, y no tiene nada de anestesiante. El sí-mismo que pacienta la alteridad, se pacienta a sí en la contingencia del encuentro, vive la vigilia y el sueño a partir de un contacto del que no puede sustraerse. La paciencia pone también el acento en el ejercicio de las capacidades. Pero la atestación, en cuanto confianza que depositamos en el despliegue de nuestras capacidades como modos de arrostrarnos nuestro ser personal, debe también dar cuenta del esfuerzo y la fatiga que conllevan. A cada capacidad le corresponde un esfuerzo y una fatiga, pues cada capacidad está enraizada en un cuerpo vivido que es órgano de nuestro

28 E. HOUSSET, «Le douceur de la patience», en Revue d'éthique et de théologie morale, $\mathrm{N}^{\circ} 250$, septiembre 2008, 27. 
querer y fuente de motivos pero también de resistencia y opacidad. El hundimiento de las capacidades en el fenómeno de la encarnación nos vuelve primeramente presente a nosotros mismos junto con la particularidad de cada capacidad: pues me soy presente en el ejercicio de las capacidades con las que entro al mundo y lo intervengo, pero también en la fatiga que acompaña de manera irremediable el despliegue de estas. Mientras que el esfuerzo es el modo de abrirse y enviarse hacia el mundo, la fatiga hace aparecer el mundo de otro modo haciendo depender su presencia de la mía. Si en la fatiga rechazo la apertura al mundo -como cuando afirmo tras el cansancio de la lectura de la Crítica de la razón pura, ¡basta!, no puedo más-, esto no significa que lo suprimo, sino que su presencia es modificada conforme al modo como me doy y manifiesto a mí mismo. La fatiga no me cierra de modo definitivo al mundo, sino que me abre a él de manera diferente ${ }^{29}$.

7. Finalmente, respecto de la expresión homo capax, Jean-Louis Chrétien nos aporta la siguiente pista: «La palabra fundamental es aquí la de capacidad, se trata de ser capax Dei, capaz de Dios. De la raíz del verbo capere, tomar, coger, pero también contener o abrazar, capax tiene una significación espacial -el diccionario de Gaffiot indica "espacioso, amplio, extendido"-, y reenvía a la posibilidad de acoger en sí, de recibir o de contener, sea corporal o espiritual ${ }^{30}$. Desde aquí, se podría afirmar que la fenomenología de las capacidades demanda una reflexión sobre la acogida. Ser capaz es tener el poder de acoger y recibir. La capacidad es una disponibilidad al encuentro o, más precisamente, una disposición a reconocerse ya encontrado o tomado antes incluso de dar cuenta de la presencia de lo otro en mí; es decir, la capacidad es apertura y pasibilidad ante el encuentro con lo otro y es también un tipo de herida o

29 «Hablar de mundo, excúsenme la trivialidad del recordatorio, es hablar del horizonte de todo aparecer. Y en la experiencia de la fatiga, es necesario concebir que todo me aparece diferentemente -lo que quiere decir que el mundo es pura y simplemente diferente-. Estoy claramente fatigado de esto o aquello, de haber leído la Crítica de la razón pura o de haber hecho una larga excursión, pero la cosa fatigante, o la acción fatigante, tiene por notable propiedad fenomenológica el repercutir en toda otra aparición. La Crítica de la razón pura me fatiga. Pero, en el acto en que ella me fatiga ( $\mathrm{y}$ en este acto solamente, claro me será siempre posible hacer otra cosa y permitir al mundo aparecerme diferentemente), es todo el mundo, en bloque, y es aquí el punto importante, que me fatiga» [J. YVES LACOSTE, Présence et parousie (Genève 2006) 311].

30 La joie spacieuse. Essai sur la dilation (Paris 2007) 51. 
abertura imposible de cerrar o suturar. Pero, cuando se afirma que un sujeto es capaz de narrar o recordar ¿se está ante una presencia que antecede al sujeto que se encuentra encontrado? De ningún modo se puede desechar tal lógica de manera definitiva, pues ser capaz de narrar o de recordar podría ser considerado bajo la luz del encuentro, tal como uno se encuentra con otra persona: cuando narramos algo sobre alguien, por ejemplo sobre uno mismo, ¿no se pone uno en presencia de sí? Y en ocasiones, ¿̇no es tal presencia algo extraña y paradójica para el propio autor o lector del relato?, ¿no hay allí una relación consigo mismo teñida por un extrañamiento de sí, como si uno fuera otro, cuando el propio relato me pone en juego como lector o incluso como autor? Y ¿cuál ha sido el tiempo de ese otro? Ese otro que yo mismo soy, ¿me antecede, es mi contemporáneo o su presencia ha sido tan furtiva y fugaz que no tiene más consistencia que la de una imaginería cualquiera?

No se puede entender el homo capax solo en el sentido activo del «yo puedo" porque el poder que el sujeto dispone es al mismo tiempo la posibilidad inscrita de la recepción de lo otro, de sí, de sí mismo como otro y de lo otro como sí mismo. Pero, el texto de Chrétien también acentúa el modo de ser espacioso del hombre capaz. La tesis del autor de la Joie spacieuse es que el sí-mismo no solo es despertado a sí y a lo otro a partir del contacto o del encuentro con Dios, sino que siendo acogido este último, dilata, distiende y extiende el alma de quien se halla a sí encontrado por Dios. La dilatación es el proceso a partir del cual el hombre «va a devenir, cada vez más, capaz de Dios» ${ }^{31}$. Pero, dilatación o espaciamiento es también alegría y gozo de ser a imagen de Dios, vale decir creatura. Que la persona se dé a sí y se arrostre su ser, significa que se halla en el espaciamiento abierto y promovido por lo otro en uno mismo. No hay cómo dar consigo mismo si no es por el espacio que abre la alteridad en el sujeto. Y en este sentido, la ipseidad del sí-mismo se define como el modo de ser de la persona abierta al encuentro con las múltiples figuras de la alteridad: pues estar abierto a..., es también exponerse para la afectación. Lo que nos lleva a un siguiente punto destacable: el espaciamiento como pasibilidad puede ser entendido como una feliz afectación. Lo que está en juego es la dialéctica entre lo finito y lo infinito que determina la presencia del sí-mismo. Lo relevante es el modo como el sujeto se resuelve con relación a su finitud y se abre

$31 \quad$ Ibid., p. 52. 
a su conquista y superación: un sujeto opaco para sí mismo pero que comprende la tarea de su conquista como un largo itinerario. La feliz afectación es el modo de resolverse a favor de sí a partir de un primer encuentro consigo marcado por el descubrimiento de la finitud, pero también por el anhelo de su superación.

En suma, la capacidad que somos no es un mero entrelazamiento flojo entre acogida e iniciativa, sino que un complejo haz de relaciones en las que hombre está siempre implicado y afectado.

Resumen: El presente ensayo intenta reflexionar sobre algunas características estructurales del homo capax tal como ha sido pensado por Ricoeur de modo explícito a partir de su obra de 1990, Soi-même comme un autre. Así, lo que interrogaremos no son las capacidades que Ricoeur analiza a partir de 1990, poder actuar, decir, narrar y narrarse, y considerarse imputable de las consecuencias de sus acciones, sino el ser capaz mismo. ¿Qué significa ser capaz? ¿Se trata como lo afirma el propio Ricoeur de un carácter esencial de la humanidad del hombre? ¿Es un a priori por tanto? La tesis que quisiéramos defender son, primero que el trasfondo de la capacidad es su ser en relación y la pasibilidad, y segundo que solo en el encuentro con lo otro el ser capaz estiliza sus poderes con los que se abrirá al mundo.

Palabras clave: Ricoeur, homo capax, ser en relación, paciencia, afirmación.

Abstract: This essay aims to reflect on some structural characteristics of the homo capax as it has been explicitly conceived by Ricoeur since his 1990 work, Soi-même comme un autre. What we examine are not the capabilities that Ricoeur analyzes starting in 1990, to be able to act, speak, narrate, and be narrated, and to be regarded as attributable to the consequences of one's actions, but rather the capable human being itself. What does it mean to be capable? Is it, as Ricoeur himself says, part of the essential nature of man's humanity? Is it therefore a priori? The thesis that we would like to defend is that, first, the background of capability is man's being in relation and passibility, and second, only in encounters with the other does the capable human being stylize the powers with which it opens the world.

Keywords: Ricoeur, homo capax, being in relation, patience, affirmation. 